\title{
ADALBERTO PERNAMBUCO NOGUEIRA: PESQUISADOR E LÍDER RELIGIOSO DO RIO GRANDE DO SUL
}

\author{
ADALBERTO PERNAMBUCO NOGUEIRA: RESEARCHER AND RELIGIOUS
} LEADER FROM RIO GRANDE DO SUL

\section{Mundicarmo Ferretti ${ }^{1}$}

Adalberto Pernambuco Nogueira, Pai Pernambuco, é um dos grandes pesquisadores de religião de matriz africana do Rio Grande do Sul que alia competência religiosa e erudição, pois acompanhou por muitos anos a trajetória da religião afro-brasileira daquele estado participando intensamente das atividades realizadas por diversas casas de culto, realizando entrevistas com os mais velhos, interagindo com pesquisadores e analisando a literatura sobre religiāo afro-brasileira. Essas características aparecem claramente em quatro textos de sua autoria que nos propomos comentar aqui na seção Debates da Revista Debates do NER/RS: "A cultura religiosa negra do Rio Grande do Sul", "As religióes africanas no Rio Grande do Sul (Batuque)", "Da importância dos mercados para as religiōes afro-brasileiras" e "O nosso mercado público e os orixás”. Nesses trabalhos Pai Pernambuco dá uma visáo geral sobre a religiáo de matriz africana do Rio Grande do Sul, sobre as pesquisas ali realizadas e sobre a literatura publicada sobre ela, acompanhada de comentário crítico. E faz também referência a registros realizados por pesquisadores que já não estáo entre nós, inclusive a alguns que se perderam e que poderiam ter sido adquiridos por órgãos de pesquisa do estado ou que foram destruídos por eles ou por seus familiares e não puderam ser conhecidos pelos mais novos.

1 Mundicarmo Maria Rocha Ferretti - Dra. em Antropologia; Professora Titular da UEMA; Professora do Programa de Pós-graduação em Ciências Sociais da UFMA; Coordenadora do Grupo de Pesquisa “Religião e Cultura Popular” - GP-Mina; Pesquisadora de Religião afro-brasileira, cultura popular e folclore, Brasil. E-mail: mundicarmorf@gmail.com. 
Conheci Pai Pernambuco quando estive em Porto Alegre, a convite do CEUCAB/RS, como palestrante do II SEMINÁRIO CULTURAL E TEOLÓGICO DA UMBANDA E DAS RELIGIÓES AFROBRASILEIRAS. Meu texto, intitulado "O Culto aos caboclos no Maranhão" foi publicado em dezembro de 1996 e janeiro de 1997 em "O Triângulo Sagrado” - periódico daquela instituição, fundada e dirigida por ele. Soube naquela ocasião que, apesar de ter nascido em Belém/PA, era uma das principais lideranças da religiáo afro-brasileira do Rio Grande do Sul. É possível que tenha saído muito cedo de sua terra natal e que tenha conhecido ou se dedicado à religiáo afro-brasileira já no Rio Grande do Sul. Lembro dele ter comentado após a minha palestra que a palavra Cabinda, tão conhecida na religiáo afro do Rio Grande do Sul, era pronunciada no Maranhão de forma anasalada - "Cambinda", mas não lembro de tê-lo ouvido falar ou fazer referência em seus textos, aos encantados da família de Rei da Turquia (Jarina, Mariana) e aos de Codó, como Légua Bogi-Buá da Trindade, muito conhecidos nos terreiros do Pará e também do Maranhão e do Piauí, que revelaria a sua identidade paraense.

Dois dos quatro artigos que nos propomos comentar agora apresentam a religião afro do Rio Grande do Sul, em especial de Porto Alegre, na sua trajetória e diversidade, estabelecendo comparaçóes principalmente com o Candomblé da Bahia, pesquisado por grandes mestres, como Roger Bastide, e amplamente divulgado em obras clássicas de religião afro-brasileira onde geralmente é apresentado como "a religião afro verdadeira". No primeiro deles: "A cultura religiosa negra no Rio Grande do Sul", apresentado em conferência proferida em Fórum promovido pela Fundação Palmares, Pai Pernambuco se apresenta como religioso afro-brasileiro (Ojuobá), com mais de 40 anos de dedicação à sua religião, e como estudioso de religióes afro brasileiras sem titulo acadêmico. Agradece a sua indicação para participar daquele evento ao pesquisador e amigo Dr. Ari Pedro Oro de quem se orgulha de ter sido fonte de consulta em suas pesquisas antropológicas.

Naquele trabalho Pai Pernambuco explica, em parte, a diferença do Batuque para o Candomblé da Bahia em virtude do Rio Grande do Sul náo ter recebido navios negreiros e por seus primeiros africanos ou afrodescendentes - de 
várias etnias e esposando uma religiáo menos pura do que os que iniciaram os primeiros terreiros da Bahia -, já terem vindo de outros estados brasileiros (como integrantes das entradas e bandeiras ou importados pelos donos de charqueadas) ou pertencerem a nações não identificadas, vindos do Uruguai e da Argentina. Informa também naquele trabalho que a penetração do Candomblé tradicional no Rio Grande do Sul ocorrera há menos de dez anos e que naquela época era praticado em poucas casas.

Segundo Pai Pernambuco, a grande maioria das casas de culto afro do Rio Grande do Sul, perto de 98\%, eram de Batuque (ou de Nação, como apresentadas mais usualmente), distribuídas em cinco denominaçóes: Jeje (quase extinta, onde se tocava tambor com aguidavís e realizava rezas mais ligeiras); Ijexá (a predominante, cultuando os 12 orixás homenageados nos terreiros de Porto Alegre/RS); Oyó (definida por poucas casas, que realizam a obrigação das cabeças (onde orixás dançam com a cabeça de animais ofertados na boca, as vezes em estado de putrefação); Cabinda (que apresenta como de origem daomeana, afirmada por várias casas onde se canta para Legbara); e Nagô (em extinção quase total, assumida, na época em que apresentou o seu trabalho, só por uma casa).

Conforme explicação de Pai Pernambuco, além da nação Ijexá ser assumida pela maioria dos terreiros, algumas casas de culto do Rio Grande do Sul que se definiam como de outra nação seguiam também o modelo Ijexá, se diferenciando das definidas como Ijexá apenas por um ou outro ritual específico ou por alteração na ordem de chamada dos orixás nos toques. Mas, como adverte Pai Pernambuco, o Ijexá do Rio Grande do Sul não é idêntico ao da Bahia e nele são cultuados os seguintes orixás: Bará, Ogum, Yansã, Xangô, Obá, Odé, Otim, Ossanyn, Xapanã, Oxum, Yemanja e Oxalá. Entre as características que o diferem dos Ijexás de outras religióes afro-brasileiras foram por ele apresentadas: 1) no Batuque/Nação do RGS se prepara filho de Bará (entidade que corresponde a Exu) e ele participa de toda a obrigação (como as outras entidades cultuadas), daí porque no Batuque não têm padé (presente oferecido a Exu na abertura do toque/tambor e entregue a ele em sua casa,fora do salão); 2) no Batuque não há paramentação de orixás e as 
vestimentas de luxo, tão usadas no Candomblé, são de uso recentes; 3) em quase todas as casas de religião afro do Rio Grande do Sul não se permite fotos e outros registros de imagem de pessoas com orixás (em transe); 4) geralmente nos toques do Batuque os orixás incorporados permanecem na parte central da gira; 5) e no Batuque os orixás incorporados se dirigem aos fieis verbalmente dando conselhos e consolando-os.

Pai Pernambuco aponta também varias cerimonias do Batuque que não são realizadas no Candomblé: 1) Cerimonia do peixe - cerca de 4 dias após uma festa grande (matança de peixe seguida de toque, em homenagem a Orixá Funfun); 2) Mesa dos Prontos - nas festas grandes (mesa no chão para os possuidores de todos os axés, com a comida predileta de todos os orixás); 3) Balança - para Xangô Aganjú, quando tem matança de animais de quatro pés - roda dos prontos, de até 36 pessoas (quando eles são em número maior fazem duas rodas, uma para filhos de orixás do seco e outra com os de orixás das águas): de mãos entrelaçadas, fazendo movimentos para dentro e para fora da roda até a chegada de orixá, quando a roda se desfaz e os orixás ficam no centro enquanto a gira continua, integrando os não incorporados. A Balança é feita com muita seriedade, pois qualquer erro ou interrupção representa perigo para o chefe da casa e exige pedido de perdão; 4) Despacho do Ecó (para o Bará) - põe-se no centro do salão quartinhas de vários orixás e o Bará sai com elas para despachar no cruzeiro mais próximo, carregando toda a negatividade; 5) Dança de Atã - com Yansã oferecendo bebida a Ogum, que duela com Xangô, até que o primeiro é vencido pela bebida e ela parte com Xangô. Segundo Pai Pernambuco, esse ritual representa supremacia da justiça; 6) e Mesa de Ibejis - comandada por Oxum e Xangô (no encerramento da obrigação de quatro patas, antes da mesa de adultos): gira realizada com crianças de até 12 anos, em torno de mesa armada no chão, onde as comidas de orixás são substituídas por canja, frutas e doces variados.

Naquele primeiro texto aqui analisado - "A cultura religiosa negra do Rio Grande do Sul” -, Pai Pernambuco descreve ainda uma respeitada casa de Nação, de Bagé/RS, que trabalha no ritual Nagô e que apresenta grandes 
diferenças das outras casas de religião afro-brasileira daquele estado, com exceção de uma que se originou dela. É curioso que vários traços apontados por ele naquelas casas são também encontrados na "casa mãe" do Nagô do Maranhão: 1) ingresso de poucos e membros do culto escolhidos pelos orixás; 2) entrada ritualística dos médiuns no salão em fila indiana e dos orixás a medida que são puxadas as rezas; 3 ) e a possibilidade dos orixás invocados dançarem até o final do toque, embora quase sempre se retirem ao final de suas rezas, daí porque raramente se encontram na gira vários orixás diferentes. Pai Pernambuco encerra seu primeiro texto comentado aqui com um Oriki para Olorum, em português, apresentado como anexo, que não sabemos se é tradicional nas casas de Batuque rio-grandenses, se pertence à tradição de sua casa de culto, ou se é também conhecido fora do Rio Grande do Sul.

No segundo texto selecionado: "As religióes africanas no Rio Grande do Sul (Batuque)", apresentado por ele em 2000, segundo informação do Prof. Ari Oro (2014, p. 102), Pai Pernambuco "faz um apanhado geral e um retrospectivo dos cultos adotados no Rio Grande do Sul e de suas principais figuras", anuncia a chegada da nação Ketu, com a recente importação do Candomblé, e critica a junção de naçóes em decorrência de trocas ocorridas após o desaparecimento dos fundadores dos terreiros mais antigos. Nesse trabalho informa que o jeje já foi predominante no Batuque e faz referência a nomes de voduns encontrados em algumas rezas de terreiros de Batuque: da família de Kavioso - Badé (Aganju - jovem) e Bobô/Bogbo (Agodô -velho); de Sapatá (Xapanan jovem); e de Bará (corruptela de Legbara). Mas, não faz referência a importância daquelas entidades no Tambor de Mina do Maranhão e do Pará, onde a religião afro é também conhecida como batuque, tal como no Rio Grande do Sul. Trata também ali, ao final do texto, sobre a Umbanda Gaúcha (que afirma ter sido trazida em 1926 do município de Rio Grande), e dá notícia da exportação do Batuque do Rio Grande do Sul para os países de Mercosul, principalmente para a Argentina.

Pai Pernambuco registra ainda, em "As religiôes africanas no Rio Grande do Sul (Batuque)", a presença no Rio Grande do Sul de um príncipe exilado 
do Benin - o Príncipe Custódio -, que cultuava voduns, mas, segundo ele, não iniciou pessoa alguma na religiáo (o que afirma que não poderia fazer para quem náo tinha título de nobreza, não fosse africano ou filho de africanos puros, e para um branco ou mestiço), embora após o seu falecimento vários tenham se apresentado como seus filhos-de-santo, inclusive o ex-governador Borges de Medeiros, que costumava frequentar a casa daquele príncipe para fazer trabalhos para se manter no poder. Nesse particular diverge do Pesquisar Norton Corrêa, sobre quem faz alguma restriçáo (1992, p. 54). Pai Pernambuco aponta ainda naquele texto vários temas que mereciam maior atenção de pesquisadores do Batuque como: a tradição Cabinda, os terreiros Nagô e outros. Finalizando aquele trabalho, fornece informação sobre a Umbanda Gaúcha, tema não abordado no primeiro texto aqui por nós comentado.

Segundo Pai Pernambuco, os terreiros de Umbanda mais antigos do Rio Grande do Sul foram abertos em 1926, no município de Rio Grande, por Otacílio Charão, e, em 1932, na capital, por Laudelino de Souza Gomes. Segundo ele, os primeiros terreiros de Umbanda, além de perseguidos pela polícia, sob a acusação de feitiçaria, enfrentaram a oposiçáo de africanistas e kardecistas. O de Otacílio, denominado "Reino de São Jorge" era comandado espiritualmente pelo Caboclo Vira Mundo e pelo Preto Velho Girassol; utilizava em seus trabalhos de magia seiva de vegetais, flores, frutos, perfumes; e realizava seus rituais em cachoeiras, pedreiras, rios, cruzeiros e no mar, inclusive os dos aprontamentos dos médiuns. Naquele terreiro os trabalhos de incorporação eram realizados ao som de palmas e se fazia uso de bebidas e defumaçôes. Já na casa mais antiga da capital, a de Laudelino, denominada "Congregação Espírita dos Franciscanos de Umbanda", havia um espaço para trabalhos de desobsessáo, descarrego e desmanchos.

O terceiro e o quarto trabalho de Pai Pernambuco que comentaremos a seguir giram em torno da importância do mercado na África e na religiāo dos orixás no Rio Grande do Sul. Inicia o terceiro: "Da importância dos mercados para as religiōes afro-brasileiras", afirmando que na África o mercado não é apenas um local onde sáo comercializados alimentos e os diversos produtos 
do trabalho da população, mas é um local de encontro da população em determinados dias da semana, daí porque costuma ser construído no centro da aldeia ou em local conveniente à convergência da população. Lembra também que várias cidades africanas surgiram em locais onde já existia um mercado ou feira ou aqueles foram organizados logo depois da construção de suas primeiras habitaçóes e que muitos sacerdotes de Ifá faziam ali o seu ponto, embora costumassem levar seus consulentes até o templo para consultar o Ifá. No mercado os africanos costumam encontrar também animais para sacrifício e materiais necessários ao culto religioso, às vezes não encontrados na sua região. Lembra ainda que o mercado africano é também conhecido como uma das casas do Bará (Exu), o "dono do mercado", daí porque os visitantes costumam passar pelo mercado logo que chegam a uma cidade. E que, por essa razão, os mercados não podem ser facilmente abolidos com a modernizaçáo das cidades e construçáo de supermercados. Pernambuco assinala que na entrada dos mercados africanos existe um assentamento sumário onde sáo depositados os tributos a Exu, "senhor dos limiares e das passagens", para que ele auxilie nas transaçôes comerciais ali realizadas.

Falando sobre a reforma do Mercado Público de Porto Alegre, realizada em 1990, Pai Pernambuco comenta que a banca central do mercado antigo foi removida, dando lugar a uma encruzilhada com o centro demarcado por um mosaico, onde se encontraria o assentamento do Bará. Informa que em suas reformas, o Mercado Público de Porto Alegre perdeu algumas características religiosas africanas em nome da modernização, que ficaram apenas na lembrança do tempo em que africanos enchiam seus corredores. A venda de ervas, por exemplo, foi muito reduzida, restando principalmente as resinas e essências para banhos ritualísticos.

Como explica o nosso sacerdote e pesquisador, no Rio Grande do Sul, o mercado deve ser visitado por pesquisadores e iniciados na religiáo dos orixás. Nas primeiras visitas o aspirante é acompanhado por um dos mais velhos, que conhece os elementos da nota recebida do sacerdote para aquisição e tem conhecimento da importância de cada um deles. Depois o aspirante volta várias vezes para adquirir ingredientes para "trabalhos" ou 
para ritos iniciáticos e, ao termino de sua iniciação é feito no Rio Grande do Sul o "passeio" pelo mercado seguindo o mesmo itinerário dos primeiros. Pai Pernambuco acrescenta que ali não é mais realizado o passeio pelo mercado quando há desencarne de praticante de culto afro, como ocorre na África. E adianta que no passado as casas especializadas em artigos religiosos, as floras, eram localizadas no mercado e seus proprietários eram pessoas ligadas a religião, o que já não mais existe.

O último texto de Pai Pernambuco incluído na seleção que estamos comentando, intitulado "O nosso mercado público e os orixás", versa especialmente sobre o mercado público de Porto Alegre e sobre a influência africana no Rio Grande do Sul, apoiado em suas vivências e no depoimento de pessoas idosas com quem que ele teve a oportunidade de conviver. Apesar de retomar algumas ideias apresentadas no artigo anterior, nesse último texto Pai Pernambuco apresenta a cidade de Porto Alegre como marcada pela presença africana e repleta de espaços ocupados no passado por africanos e seus descendentes, dificilmente imaginada por afro-brasileiros de outras partes do Brasil. E, lamentando a inexistência de pesquisas sobre vários daqueles espaços, o autor "sonha" com um momento em que estudiosos da cultura de matriz africana ("pesquisadores de escola") se debrucem sobre eles e ampliem o que se sabe a respeito deles e o conhecimento de sua importância para o Rio Grande do Sul.

Pai Pernambuco registra em "O nosso mercado público e os orixás”, mais do que nos três textos comentados anteriormente, lembranças de suas visitas ao mercado público de Porto Alegre, em diversas épocas, e a memória de pessoas mais velhas, com quem conviveu, sobre tempos mais afastados, quando aquele mercado era movimentado principalmente por africanos e os babalaôs faziam ponto ali e eram contatados por pessoas que desejosas de consultar o Ifá para a compreensão de seu destino e para a tomada de decisóes importantes para as suas vidas. Nesse texto, rico em detalhes, Pai Pernambuco registra informações que não devem ser possuídas por muitos iniciados no culto dos orixás do Rio Grande do Sul e que parecem também não serem facilmente localizados na literatura sobre a cultura negra daquele estado, embora aquele 
último texto tenha sido citado em 2014, de forma elogiosa, na Revista Pós de Ciências Sociais, da UFMA, pelo pesquisador Ari Oro.

Com efeito, tal como apresentado no artigo de Pai Pernambuco, o Mercado Público de Porto Alegre parece arquitetado por africanos, e sua arquitetura parece embasada pela religiáo dos orixás o que, apesar das perdas acarretadas em cada uma de suas reformas, permanece visível aos iniciados. Segundo ele, o prédio se compóe de um quadrado cortado por uma cruz, com uma banca ao centro, regida pela falange de Ogum, orixá da demanda e da agricultura, que detém também o poder da faca, e cada uma de suas quatro vias internas tem sua significação e uma entidade que preside.

O texto sobre o Mercado Público de Porto Alegre traz também informaçáo sobre as atividades realizadas ali no passado por africanos e como eles sáo lembrados pelo povo do Batuque. Segundo ele, em seus corredores eram encontradas sentadas várias negras-mina vestidas de chita, com pano à cabeça, fumando muito cigarros, cachimbos e charutos e exibindo no colo variados patuás, que eram vendidos por elas e cuja venda garantia a sua subsistência. Essas pretas-mina são descritas por ele como:

Magras, quase secas, canelas finas, faces inescrutáveis e cobertas de rugas, elas se constituíam em algo que jamais poderá ser revivido. E era patente o cuidado dos que a eles se dirigiam em jamais as melindrar, táo forte era a fama de feiticeiras que desfrutavam.

Pai Pernambuco cita em seguida um caso envolvendo um irreverente frequentador do mercado e uma negra velha que lhe pedira um cigarro e fora por ele objeto de zombaria e que, ameaçado por ela foi atropelado e morto logo em seguida. Uma versão desse caso foi também apresentada pelo pesquisador Norton Corrêa (1992, p. 52), em sua dissertação de mestrado em Antropologia, defendida em 1989 e publicada em 1992. Segundo Pai Pernambuco, enquanto as negras-mina permaneciam sentadas nos corredores, os homens circulavam pelo mercado com suas camisas de física, calças de riscado presas por suspensório, chinelos de couro e com suas cabeças cobertas por amoletes (espécie de toucas 
usadas para proteção), e só paravam quando abordados por outro frequentador, às vezes em busca de orientação e não raro encaminhado por eles aos especialistas em jogo de cawris (búzios). Os mina eram tidos como conhecedores da magia, daí a frase tantas vezes repetida pelos mais novos: "No tempo dos mina eles, só com uma pomba, faziam chover; hoje, nem com um pombal nós o conseguimos".

Encerrando nossos comentários sobre quatro textos de Adalberto Pernambuco Nogueira gostaria de ressaltar que, apesar de ter uma visão crítica sobre as pesquisas científicas e de divergir de algumas informaçóes e interpretaçóes apresentadas por pesquisadores "de escola”, Pai Pernambuco reconhece a contribuiçáo que ela pode trazer para o conhecimento da origem e trajetória da religião dos orixás no Rio Grande do Sul e contribuir para o preenchimento de lacunas existentes na visão baseada na oralidade e para o registro para as novas geraçôes da memória dos antigos em vias de desaparecimento e deterioração.

\section{REFERÊNCIAS}

CORRÊA, N. F. O Batuque do Rio Grande do Sul: Antropologia de uma religião afro-rio-grandense. Porto Alegre: Ed. da UFRGS, 1992.

FERRETTI, M. O Culto aos caboclos no Maranhão. O Triangulo Sagrado, dezembro de 1996 e janeiro de 1997. Apresentado no II Seminário Cultural e Teológico da Umbanda e das Religióes Afrobrasileiras, CEUCAB/RS.

$\mathrm{ORO}, \mathrm{A}$. P. As religiōes afro-riograndenses na visão de dez agentes religiosos que já partiram. Rev. Pós Ciências Sociais, v. 11, n. 21, jan./jun. 2014, p. 85-103.

Recebido em: 20/01/2019

Aprovado em: 20/01/2019 